\title{
Lymphocytic Neoplasm
}

National Cancer Institute

\section{Source}

National Cancer Institute. Lymphocytic Neoplasm. NCI Thesaurus. Code C7065.

A neoplasm composed of a lymphocytic cell population which is usually malignant (clonal) by molecular genetic and/or immunophenotypic analysis. Lymphocytic neoplasms include Hodgkin and non-Hodgkin lymphomas, acute and chronic lymphocytic leukemias, and plasma cell neoplasms. 